\title{
Educação física, cultura e a produção de significados
}

\section{Physical education, culture and the production of meanings}

\author{
Quéfren Weld Cardozo Nogueira*
}

\begin{abstract}
RESUMO
O presente texto executa análises que buscam compreender como a Educação Física realiza discussões, tendo como estratégia central a cultura, abrindo espaços para se discutir como o significado é também uma construção cultural. A centralidade da dimensão simbólica da cultura representa uma forma de análise em que a produção, distribuição e acesso aos bens culturais estão envolvidos com a maneira como valorizamos ou ignoramos certos aspectos da vida social. O ponto fundamental dessa discussão refere-se à compreensão de que os sentidos e significados historicamente construídos estão inseridos num processo conflituoso em que relações de poder caracterizam um combate por significado. Nesse combate, relações sociais são desfeitas e estabelecidas, conhecimentos são produzidos e distribuídos, políticas são geradas. De posse destas discussões, a Educação Física passa a ser vista não como uma mera atividade em que são escolhidas técnicas supostamente livres de coerções, mas como uma produção e uma política cultural que participa da maneira como os significados são historicamente constituídos.

Palavras-chave: educação física, cultura, significado.
\end{abstract}

\begin{abstract}
The present text executes analyses which search to understand how Physical Education uses the cultural dimension as a central strategy of its

* Mestre em Educação pela Universidade Federal de Uberlândia (UFU/MG). Docente do curso de Educação Física da Universidade Vale do Rio Doce (Univale) - Governador Valadares/
\end{abstract} MG. 
intervention, opening spaces to argue itself also as a cultural construction. The focus on the symbolic dimension of the culture represents an analysis in which the production, distribution and access to the cultural products are involved with the way we value or we ignore certain aspects of the social life. The basic point of this argument is the understanding that the directions and meanings historically constructed are inserted in a conflicting process where relations of power characterize a combat for meaning. In this combat, social relations are established, knowledge is produced and distributed, politics are generated. In this context, Physical Education is seen not as a mere activity which chooses supposedly free techniques of coercions, but as a cultural and politic production that participates in the way meanings are historically constituted.

Key-words: physical education, culture, meaning.

\section{Considerações Iniciais}

Um aspecto que vem marcando o debate educacional nos últimos anos, refere-se ao aumento de discussões que aprofundam questões relacionadas com a cultura. Não é raro encontrar em diversas publicações ou reuniões pedagógicas alusões à dimensão cultural - com os diferentes significados que tal termo possa sugerir - para fundamentar ações e intervenções escolares. Neste contexto, Hall (1997) evidencia que atualmente não há o nascimento de um interesse pela cultura, mas sim, a imersão em diferentes formas de tratar o mesmo tema, realizando tanto uma retomada de antigos interesses como a proposição de novas questões e elementos de análise. Tal movimento permite compreender como a cultura penetra nos diversos cantos da vida social, mediando todos os aspectos do cotidiano, das decisões tomadas e da construção de identidades e subjetividades sociais.

No campo específico da Educação Física, o diálogo com perspectivas críticas da educação ${ }^{1}$ advoga um estatuto e uma forma de intervenção capa-

1 Uma das conseqüências do movimento renovador da Educação Física na década de 1980 foi a criação de perspectivas pedagógicas preocupadas em fazer uma análise do papel social da educação numa sociedade capitalista. Nesse contexto, as perspectivas critico-superadora e crítico-emancipatória compreendem que as formas do movimentar-se humano (com destaque para o esporte) reproduzem os valores e princípios da sociedade capitalista (BRACHT, 1999) 
zes de fazer com que práticas e instituições sociais como, por exemplo, as práticas esportivas, que não eram tradicionalmente consideradas culturais, sejam concebidas a partir dessa dimensão. As discussões sobre a cultura procuram, por um lado, compreender a própria Educação Física como uma produção cultural e, por outro, aguçar as nossas sensibilidades para o entendimento sobre como as práticas corporais humanas fazem parte de um contexto social que envolve aspectos políticos, econômicos, culturais, históricos, etc.

O paradigma cultural representa uma tentativa de dar um novo enfoque à Educação Física, executando, ao mesmo tempo, uma resignificação e a inserção de novas práticas corporais que constituem o universo dos conteúdos a serem trabalhados. O uso da referência cultural abre espaços para que a intervenção da Educação Física se baseie não mais, ou não somente, nos estudos do treinamento esportivo, da aprendizagem motora ou do desenvolvimento humano, mas sim, ou também, como aponta Bracht (1997), nos pressupostos sociofilosóficos da educação crítica.

Interpretando as discussões de Popkewitz (1994) sobre as práticas educacionais como um todo, pode-se afirmar que o paradigma cultural no âmbito da Educação Física representa a escolarização de um padrão discursivo dentro de uma cultura escolar que organiza, seleciona e avalia as práticas corporais humanas, como forma de descrever e interpretar o mundo, com o intuito de construir determinadas práticas e identidades sociais.

Sendo a cultura um importante elemento para fundamentar estratégias de intervenção pedagógica, este texto tem por objetivo realizar uma análise sobre como e porque a Educação Física utiliza a dimensão cultural em suas discussões. A partir disto, serão levantadas questões sobre um aspecto comum a todos os autores que discutem a Educação Física numa perspectiva crítica: a dimensão simbólica da cultura.

\section{Educação física e os usos da cultura}

As abordagens sobre a cultura no campo da Educação Física pode ser encontrado com características específicas após o surgimento nos anos 1980 de interesses acadêmicos preocupados em analisar como as práticas corporais humanas estão impregnadas de valores hegemônicos que contribuem para a manutenção da sociedade capitalista. A compreensão do corpo e dos seus 
movimentos como construções culturais apresenta-se como uma ferramenta capaz de fundamentar formas de intervenção contrárias à produção de um corpo disciplinado, obediente e servil, produto das ciências naturais ou que se diziam isentos de determinantes políticos.

Se fosse possível apontar em torno de qual afirmação giram as concepções presentes no livro Metodologia do ensino da educação física (SOAREs et al., 1992), obra de referência da perspectiva crítica-superadora em Educação Física, destacaria a seguinte:

A Educação Física é uma disciplina que trata, pedagogicamente, na escola, do conhecimento de uma área denominada aqui de cultura corporal. Ela será configurada com temas ou formas de atividades, particularmente corporais, como as nomeadas anteriormente: jogo, esporte, ginástica, dança ou outras, que constituirão seu conteúdo. $\mathrm{O}$ estudo desse conhecimento visa apreender a expressão corporal como linguagem (SOARES et al., 1992, p. 61).

Na proposta configurada por esta perspectiva, existe a redefinição do objeto de intervenção da Educação Física como sendo a cultura corporal e não mais, ou simplesmente, o movimento humano nas suas dimensões biológicas ou psicologizantes. Ainda, ao invés de afirmar que o objetivo da Educação Física é o desenvolvimento motor ou da aptidão física, compreende-se o estudo da cultura corporal como forma de permitir aos alunos apreenderem a expressão corporal como linguagem. Considerando que “(...) o que justifica fundamentalmente o empreendimento educativo é a responsabilidade de ter que transmitir e perpetuar a experiência humana como cultura" (FORQUIN, 1993, p. 14 apud BRACHT, 1997, p. 17), torna-se importante acatar a cultura corporal como objeto de estudo e intervenção pedagógica para que a Educação Física possua uma especificidade e se legitime como disciplina escolar.

Ao afirmar que a cultura corporal é uma área do conhecimento, existe a preocupação em evidenciar um saber $^{2}$ sobre as práticas corporais que deve

2 Falar de um saber sobre a cultura corporal, esta se tratando de uma dimensão da cultura que se concretiza no saber fazer, num vivenciar, por um lado, e num saber sobre esse fazer, por outro. A dimensão do saber fazer torna-se necessária para que possamos apreender a cultura em sua totalidade ao mesmo tempo em que permite que o conceito de criticidade possa abarcar elementos estéticos e éticos (BRACHT, 2001). 
ser analisado criticamente pelos alunos nas escolas. As discussões da perspectiva crítica-superadora questionam, principalmente, o que seria necessário um aluno conhecer para ser ele conhecedor dos elementos da cultura corporal. Se, numa perspectiva tradicional, tais conhecimentos se limitavam a um fazer instrumental, para a perspectiva crítica-superadora, outros temas fariam parte do conjunto de conhecimentos necessários aos alunos, como por exemplo, a compreensão dos sentidos e significados dos temas da cultura corporal e suas relações com grandes problemas sociopolíticos (ecologia, papéis sexuais, saúde pública, relações sociais de trabalho, preconceitos sociais, raciais, da deficiência, etc.). São temas como estes que permitem enxergar o papel das práticas corporais na manutenção das contradições, desigualdades e injustiças sociais presentes na sociedade capitalista.

Contrários a perspectivas que transformam as aulas num treinamento esportivo, ou seja, numa adaptação progressiva ao esforço, a perspectiva críticasuperadora utiliza o materialismo histórico-dialético como método de análise e de intervenção social. Ou seja, o objetivo é fazer com que os alunos realizem uma leitura da realidade em sua totalidade, a partir da seleção de conteúdos no universo da cultura corporal. Tal leitura busca promover uma interpretação das contradições que regem a vida social em função da superação desta realidade, tendo como foco os interesses da classe trabalhadora. $\mathrm{O}$ trabalho com os elementos da cultura corporal introduz a Educação Física no embate com visões historicamente construídas sobre o papel das práticas corporais na organização social e na constituição e distribuição das condições concretas da existência. De certa forma, pode-se afirmar que é pela cultura e na cultura que este embate ocorre.

Se, por um lado, a ênfase na cultura corporal divulgada por Soares et al. (1992) direcionava-se em problematizar o que ensinar na Educação Física sendo que essa indagacão permite problematizar o como ensinar - Kunz (2000), por outro, privilegia em suas discussões o método de ensino, admitindo que a concepção crítico-superadora deixa muitas dúvidas sobre como proceder para que a intervenção pedagógica da Educação Física seja mais do que um ensino de técnicas e táticas esportivas.

Para investigar tal questão, o autor recorre à noção de que o esporte, manifestação da cultura de movimento, se desenvolve nas escolas, tendo como referência um processo pedagógico que se resume ao ensino de técnicas e táticas espelhadas no alto rendimento. Esse tipo de tematização e organização das aulas de Educação Física é fruto de um tipo de racionalidade instrumental que impede que os alunos atinjam a maioridade racional em suas ações.

Entretanto, o se-movimentar nos esportes pode ser tematizado de outra maneira: como aquele que considera que o movimento humano é executado 
num conjunto de sentidos/significados construídos historicamente e como sendo capaz de desenvolver as competências objetiva (conhecimentos e informações para um agir competente), social (conhecimentos e estratégias para compreender as relações socioculturais) e comunicativa (forma de comunicação capaz de fazer com que o aluno compreenda o fenômeno esportivo). $\mathrm{O}$ desenvolvimento de tais competências, quando vistas em conjunto, permite que os alunos se libertem das amarras que impedem o uso da razão crítica.

Com esta visão, a Educação Física é concebida como uma práxis social inserida num contexto sociocultural e como uma intervenção política sobre a "cultura de movimento". Nesta concepção o diálogo entre o ser humano e a sociedade possui no "movimentar-se" um elemento que promove uma interação entre as diferentes esferas que compõem a vida social:

O "se-movimentar" é, assim, interpretado como uma conduta humana, onde a Pessoa do "se-movimentar" não pode simplesmente ser vista de forma isolada e abstrata, mas inserida numa rede complexa de relações e significados para com o mundo, que configura aquele "acontecimento relacional", onde se dá o diálogo entre o Homem e o Mundo. O "semovimentar" é, então, uma conduta significativa, um acontecimento mediado por uma relação significativa (KUNZ, 1991, p. 174 apud DAOLIO, 2004, p. 37).

Esta proposta, denominada perspectiva crítica-emancipatória, pressupõe o entendimento de que é tarefa da Educação e, conseqüentemente, da Educação Física, fazer com que os alunos atinjam uma maioridade intelectual conseguida pelo esclarecimento racional. Tal tipo de esclarecimento ocorre num processo comunicativo, exigindo, portanto, o desenvolvimento de uma didática comunicativa, a qual, por sua vez, baseia-se num tipo de racionalidade que é intersubjetiva e se concretiza nos diálogos exercidos entre os agentes sociais, e não em fundamentalismos ou sistemas fechados. Assim,

A racionalidade não se funda no princípio da subjetividade, no eu, mas no diálogo, no nós, pois é intersubjetiva e, nas palavras de Habermas, dialógica. $\mathrm{O}$ contraste de pareceres e de razões é a base e o instrumento da racionalidade após a mudança hermenêutica. Dessa perspectiva, está claro que a racionalidade não pode ser excludente, e que todos os que 
têm algo a dizer são convidados a participar. Portanto, ficamos longe de qualquer fundamentalismo quando apelamos para a racionalidade ou para a tradição como critério de referencia básico para guiar na seleção e no desenvolvimento dos conteúdos e das práticas de ensinoaprendizagem. (SACRISTAN, 2000, p. 51).

O diálogo abre perspectivas para mudanças, pois permite que uma realidade seja compreendida como mutável e sujeita a diversas interpretações. Neste contexto, a cultura de movimento não possui como referência necessária as dimensões apresentadas pelo esporte de alto rendimento, mas na maneira como as diferentes práticas corporais são executadas de acordo com os sentidos e significados historicamente construídos. Desenvolver uma consciência emancipada, liberta das formas de opressão, pressupõe um processo comunicativo e educativo em que a cultura de movimento fornece elementos para que, numa aula de Educação Física não somente a linguagem corporal seja desenvolvida, mas principalmente a linguagem verbal. A capacidade de agir criticamente frente à realidade só é possível, portanto, quando se adere a uma didática comunicativa, em que os argumentos são expostos coletivamente para que as melhores ações que influenciam a vida das pessoas possam ser tomadas.

Noutro contexto, e sem a preocupação de construir uma perspectiva pedagógica capaz de se auto-denominar crítica, Daolio (1997), recorre a referenciais antropológicos para apresentar as conseqüências da dimensão cultural nas aulas de Educação Física. Citando Mauss (1974), Daolio apresenta a noção de que a história acumulada de uma determinada sociedade deixa as suas marcas no corpo e, por esse motivo, as maneiras como as pessoas sabem servir-se de seus corpos em cada sociedade são chamadas de técnicas corporais.

As conseqüências dessa perspectiva para as aulas de Educação Física encontram-se na possibilidade dos professores ampliarem o acervo dos alunos, levando em consideração que as técnicas corporais aprendidas culturalmente possuem significados diferenciados para aqueles que as praticam. Sendo assim, é possível trabalhar nas aulas com as diversas dimensões que envolvem uma prática corporal. Como exemplo, no caso do esporte: "como essa prática chegou a nosso país? A que interesses sociais ela responde? Quando foi inventada? Qual a história das suas técnicas? Como podem ser modificadas?" (DAOLIO, 1997, p. 33).

Com isso, as técnicas esportivas são compreendidas não somente como um conjunto de adaptações biológicas, mas resultado dos valores e princípios 
de uma sociedade que impregnam marcas nos gestos e movimentos humanos. Há a concepção de que as nossas capacidades biológicas se expressam e se desenvolvem em dependência com as influências culturais, a tal ponto de ser impossível uma separação entre estas dimensões. Assim, uma técnica esportiva não é apenas uma forma de executar um movimento de maneira mais eficiente, mas também é resultado das marcas sociais impressas no corpo. Conseqüentemente, atuar sobre o corpo significa atuar sobre os princípios e valores que regem determinada sociedade.

Nas discussões sobre o paradigma cultural na Educação Física, também merece destaque a utilização por Taborda de Oliveira (1997;2003) da noção de corporalidade para compreender as relações existentes entre Educação, Educação Física, corpo e cultura. $\mathrm{O}$ referido autor tem se preocupado não apenas em aceitar a cultura como elemento indispensável para se entender as práticas educacionais, mas também em aprofundar e problematizar a referência cultural como suporte das intervenções pedagógicas. Isto porque, acatar a cultura como elemento essencial para a educação significa compreender a própria produção cultural longe de uma visão redentora, pois “(...) conhecimento é cultura. E cultura também são hábitos, valores, práticas, todos formas diversas do gênio humano, assim como o são, dialeticamente, o preconceito, os estereótipos, os tabus, os processos de violência e dominação" (TABORDA DE OLIVEIRA, 2003, p. 169).

Considerando a Educação Física indispensável para a construção de um projeto de formação humana que contemple a totalidade e complexidade da vida social, para o autor, é preciso pensar a construção histórica da vida humana a partir do conceito de corporalidade, pois este traz consigo a noção de que no corpo encontram-se marcadas todas as condições de vida - materiais e simbólicas - nas quais as pessoas se encontram envolvidas.

As discussões sobre a Educação Física como disciplina escolar centramse nas possibilidades formativas das condições objetivas da cultura, buscando uma problematização sobre como o corpo vem sendo marcado pela história. Nesta discussão, a noção de corporalidade pode ser tida como um eixo de organização da própria dinâmica escolar, já que nas relações entre corpo e cultura encerram-se as diversas contradições e elementos constitutivos da vida e da formação humana em sua plenitude. Neste contexto, a Educação Física pode ser vista com a seguinte especificidade:

Em nossos currículos "quem" ou "o quê" aborda questões referentes aos preconceitos raciais, às divergências étnicas, aos conflitos de classe 
manifestos no corpo, às relações de gênero e à definição dos papéis sexuais no contexto societário, à violência, à sexualidade, ao consumo de drogas? Não são questões pertencentes ao modelo de sociedade que desenvolvemos? Não são questões a que estão expostos os sujeitos em nossa cultura, principalmente nossos educandos? Não são questões que conformam novas formas de relação e convívio social? Não são relações que se manifestam explicitamente através de práticas corporais? (TABORDA DE OLIVEIRA, 1997, p. 97)

Outra discussão realizada no campo da Educação Física é realizada por Vago $(1995 ; 1999 ; 2003)$. Para o autor, a escola é um espaço social onde as relações humanas possuem um papel privilegiado para conhecermos de forma crítica o tempo presente. Entretanto, este conhecer requer “(...) reconhecer-se como pessoa que tem o que fazer nesse tempo, para construir o presente e o futuro. Uma escola viva, aberta à pergunta, à dúvida, ao conflito, à produção de novas idéias, a reinvenção de outras" (VAGO, 1995, p. 21).

Vago (1999) entende a escola como um espaço dinâmico, aberto a mudanças e onde novas possibilidades de vida são inventadas. Como lugar construído historicamente e que se organiza de acordo com diversos dispositivos (científicos, religiosos, políticos e pedagógicos), a escola produz uma cultura específica, a cultura escolar, na sua interação e tensão com diversas outras culturas. Parte-se para uma concepção em que as disciplinas escolares são vistas como "entidades culturais", locais concretos de intervenção para a construção histórica e cultural de uma sociedade e a cultura escolar como construída numa "tensão permanente" entre as práticas culturais que compõem a vida social.

É neste ambiente de produção cultural que a Educação Física faz-se presente. A concepção de cultura escolar de Educação Física, defendida por Vago, invoca um exercício contínuo de interrogação e problematização dos princípios e valores que regem as manifestações culturais, como por exemplo, os conflitos de classe, raça, gênero, idade, etc. em função de outros que afirmem a participação coletiva e a cidadania. Por se tratar de uma concepção que entende a construção da vida social como dinâmica, é possível vislumbrar a Educação Física como um espaço de enriquecimento da experiência humana, rompendo com a tendência de transformação das aulas num treinamento esportivo. Esta dinâmica possibilita a construção de uma cultura escolar de Educação Física em que os sentidos e significados para as práticas corporais penetrem no âmbito escolar, sendo aceitas ou negadas, reproduzidas e transformadas num processo de intervenção e trabalho especificamente humano. 
Enfim, apesar da dimensão cultural ter sido fonte principal para propor formas de intervenção, de desconfiar e questionar a ordem social vigente, tal elemento é utilizado com intenções contrárias a este objetivo. Um exemplo disso é o trabalho de Greco e Benda (1998, p. 14), em que os autores afirmam que "o aluno está sempre em fase de iniciação ao esporte (iniciação à técnica, iniciação ao jogo) sem que exista o jogo propriamente dito, a aprendizagem, o prazer, enfim, o que é básico e necessário para o conhecimento de alguma forma dentro da paleta da cultura corporal".

A cultura corporal é utilizada num contexto em que o estudo das práticas corporais é limitado aos campos da aprendizagem motora e treinamento técnico/tático das modalidades esportivas. Os autores afirmam que os alunos devem contextualizar o jogo dentro de um marco sociopolítico e cultural capaz de desenvolver valores relacionados à integração, socialização e aprendizagem de comportamentos específicos. Ora, já se sabe desde Bracht (1986), que os discursos que historicamente elegem o papel do esporte como fonte de socialização dos indivíduos sustentam mecanismos de controle social e adaptação das pessoas aos valores que dão suporte às condições de desigualdade e injustiça social.

O trabalho de Greco e Benda (1998) revalida tal concepção para o contexto atual:

... sabemos também que hoje, no esporte de alto rendimento, é necessário que o atleta seja independente, inteligente e decidido. Tudo isso supõe um alto nível de liberdade de ação. Portanto, é urgente e necessário que o processo de ensino-aprendizagem-treinamento que se oferece permita a aquisição de vivências esportivas que possam dar sustentação ao indivíduo, ao de defrontar com tais exigências. A isso acrescentamos que o denominado mundo globalizado também apresenta desafios nos quais a capacidade de percepção e de tomada de decisão são altamente requisitadas (GRECO; BENDA, 1998, p. 18).

Nesta perspectiva, a Educação Física seria justificada pelas exigências que a organização da sociedade capitalista nos faz. Seria papel do professsor/ treinador criar tarefas-problemas para que o aluno/atleta aprenda a tomar decisões rápidas e eficazes, pois essas são as exigências que o esporte de alto rendimento nos coloca. Se, noutro momento histórico, a escola teve um papel essencial para a produção de trabalhadores obedientes e servis; hoje a escola 
e a Educação Física são chamadas a preparar pessoas capazes de tomar decisões rápidas que a própria cultura do descartável demanda.

Após todas essas colocações, pode-se perceber que diversos são os usos da dimensão cultural no âmbito da Educação Física, sendo possível realizar diversos estudos que possam compreender as nuances entres elas. Mesmo levando em consideração as diferenças existentes entre as apropriações da dimensão cultural no âmbito das discussões pedagógicas, torna-se importante em todas as perspectivas críticas aceitar o corpo, as práticas corporais e a própria disciplina Educação Física como carregados de sentidos e significados da sociedade em que elas se encontram. Ou seja, uma das principais conseqüências destas discussões é um olhar que nos "(...) remete ao entendimento de que as práticas ou, se melhor nos convier, os conteúdos, presentes na cultura corporal de movimento, são produções humanas carregadas de sentidos e significados" (ALVES, 2003, p. 96).

Neste contexto, gostaria de direcionar minhas atenções para refletir sobre a cultura no que se refere aos seus aspectos simbólicos, como um elemento capaz de melhor compreender o papel da Educação Física como prática pedagógica.

\section{A dimensão simbólica da cultura}

Como pôde ser visto nas discussões até então realizadas, as apropriações do paradigma cultural dentro da Educação Física são diversas, sendo utilizado por muitos autores de diferentes formas. A grosso modo, duas são as conseqüências quando se estabelecem as relações entre educação e cultura:

a) a educação realiza a cultura como memória viva, reativação incessante e sempre ameaçada, fio precário e promessa necessária de continuidade humana;

b) uma teoria cultural da educação vê a educação, a pedagogia e o currículo como campos de conflito simbólicos, como arenas contestadas na busca da imposição de significados e de hegemonia cultural (SILVA, 1993 apud BRACHT, 1997, p. 17). 
Direcionando as minhas análises particularmente para o segundo tópico apresentado, adentrar neste campo simbólico promove possibilidades para se perceber como nós, seres humanos, nos organizamos para vivermos em sociedade, o papel das instituições sociais, as relações sociais construídas, as condições concretas de existência, etc., tendo como referência a noção de que as práticas corporais medeiam tais elementos que constituem a vida social.

A ênfase nas discussões que envolvem os aspectos simbólicos da cultura permite um diálogo com autores como Brandão (2002). Isso porque seus interesses se direcionam para compreender a cultura como tudo aquilo que nós, seres humanos, inventamos, a partir daquilo que recebemos, para viver e habitar nesse mundo, numa experiência extraordinária de vida: a humana. A cultura é uma tentativa incessante de aprendizagem sobre como viver nesse mundo que criamos e recriamos. Uma criação pelo caminho do sentimento, do sentido, do significado e da sociabilidade. Vivemos, portanto em "cenários de cultura" que são incorporados nos convívios diários que possuímos com outras pessoas para fazer com que a experiência individual faça do ser humano um ser cultural.

Todavia, nos basta somente criar coisas, mas é preciso também destinar significados a tudo aquilo que criamos, que recebemos, reproduzimos e produzimos. Ou seja,

O que importa é a nossa capacidade e também a nossa fatalidade de atribuirmos significados múltiplos e transformáveis ao que fazemos, ao que criamos, aos modos sociais pelos quais fazemos e criamos e, finalmente, ao que criamos, e, finalmente, a nós mesmos significados. Pois a ave que pousa num galho da árvore, a árvore é o galho do pouso, é a sombra, o abrigo, a referência no espaço e o fruto. Para nós ela é muito mais. É um nome, uma lembrança, uma tecnologia de cultivo e de aproveitamento. É uma imagem carregada de afetos, o objeto de tela de um pintor, um poema, uma possível morada de um deus ou, quem sabe? (BRANDÃO, 2002, p. 23).

A análise da cultura como bem simbólico distancia o seu entendimento como produto, objeto acabado, e se direciona para a percepção do processo social de produção cultural; processo esse que ligado a um significado atreve-se a produzir a própria vida humana. É o significado que proporciona a vida humana, pois é em volta dele que as relações entre as pessoas são con- 
cretizadas. Sendo assim, é o significado que coloca as manifestações sociais no plano da cultura.

A cultura como uma prática de significação, salienta Silva (2001), é concebida como uma ação, atividade, experiência, como um trabalho sobre materiais existentes, reinventando-os ou produzindo outros. A produção de significados não se dá, portanto, num vazio, mas ocorre quando o material cultural é redefinido, reinterpretado, transformado. Tem-se, portanto, o ser humano que na ação social representa o mundo de certa forma, não se submetendo aos modos cristalizados de seu entendimento, nem como uma representação pura, única e distante das relações entre as pessoas. Na visão de Hall (1997, p. 16)

\begin{abstract}
Os seres humanos são seres interpretativos, instituidores de sentido. A ação social é significativa tanto para aqueles que a praticam quanto para os que a observam: não em si mesmas mas em razão dos muitos e variados sistemas de significado que os seres humanos utilizam para definir o que significam as coisas e para codificar, organizar e regular sua conduta uns em relação aos outros. Estes sistemas ou códigos de significado dão sentido às nossas ações. Eles nos permitem interpretar significativamente as ações alheias. Tomados em seu conjunto, eles constituem nossas "culturas". Contribuem para assegurar que toda ação social é "cultural", que todas as práticas sociais expressam ou comunicam um significado e, neste sentido, são práticas de significação.
\end{abstract}

Interpretando a cultura como prática de significação, os significados não são vistos como falsos ou verdadeiros, mas representam uma determinada posição no jogo conflituoso em que relações de poder estão em combate. Isto porque significar pode ser entendido também como uma tentativa inconstante de fazer sobreposição de significados particulares de grupos sociais sobre outros. Situados num campo contestado, disputado e conflituoso que carrega consigo o caráter da incerteza, da imprevisibilidade, as relações de poder não esgotam a produção de significados, mas fazem dele um processo constante de produção de sentido. A produção de significados é, em si, um jogo de poder - tumultuado e conflituoso, já que há uma luta para que determinados significados se tornem hegemônicos - estando presente tanto no resultado como na origem do processo (SILVA, 2001). 
Conceber práticas culturais como relações de poder implica ver o campo de produção de significado e de sentido como contestado, disputado, conflitivo. A luta por significado é uma luta por hegemonia, por predomínio, em que o significado é, ao mesmo tempo, objeto e meio, objetivo e instrumento. $\mathrm{O}$ caráter incerto, indeterminado, incontido do processo de significação, por sua vez, faz com que o resultado dessa luta não seja, nunca, garantido, previsível. As relações de poder dirigem o processo de significações: elas, entretanto, não o esgotam, não realizam plenamente (SILVA, 2001, p. 24).

Nas vivências culturais, estabelecem-se confrontos e conflitos quando diferentes perspectivas entram em contato, fazendo com que as diversas expressões culturais estejam perpassadas por desigualdades e interesses. Não nos basta, portanto, aceitar que as produções humanas são carregadas de sentidos e significados, mas torna-se necessário analisar a maneira como estratégias são utilizadas para que determinados significados sejam produzidos e vistos como verdadeiros e legítimos para sustentar formas específicas de desigualdade social.

Produzimos significados, procuramos obter efeitos de sentido, no interior de grupos sociais, em relação com outros indivíduos e com outros grupos sociais. Por meio do processo de significação construímos nossa posição de sujeito e nossa posição social, a identidade cultural e social de nosso grupo, e procuramos constituir as posições e as identidades de outros indivíduos e de outros grupos. Produzimos significados e sentidos que queremos que prevaleçam relativamente aos significados e aos sentidos de outros indivíduos e de outros grupos (SILVA, 2001, p. 21).

É necessário, portanto, deixar de lado uma visão em que a cultura é vista de forma não-conflituosa, harmoniosa e consensual e partir para uma concepção em que os significados das práticas sociais sejam vistos como resultado de relações conflituosas e assimétricas de poder, numa tentativa de impor certos significados em detrimento de outros. Segundo Garcia (1996), no campo das relações de poder, a cultura e a política tornam-se campos de práticas constituídas pela ação contínua dos sujeitos, como espaços dinâmicos em que a cultura pode ser vista nos seus aspectos sociopolíticos e a política considerando aspectos simbólicos da cultura. 
Não nos basta aceitar que o campo de discussão sobre a cultura envolve a produção de significados, mas sim como as nossas visões mais arraigadas sobre questões sociais, éticas, políticas, estéticas, econômicas são vistas como verdadeiras e estão relacionadas com situações de discriminação e injustiça social. É um jogo conflituoso e assimétrico de poder em que as noções que possuímos sobre negros, índios, homossexuais, idosos, mulheres, crianças, adolescentes, moradores de rua, etc., se sustentam com o aporte das condições concretas da existência e das instituições sociais nelas envolvidas.

\section{Considerações finais ou sobre a educação física}

As análises aqui executadas buscaram compreender como a Educação Física realiza discussões tendo como estratégia central a cultura, abrindo espaços para se discutir os aspectos simbólicos que envolvem as práticas culturais ou como o significado é também uma construção cultural. Depois disto, foi possível adentrar em reflexões que fornecem à produção de significados um caráter político envolvido num campo conflituoso de relações de poder; num jogo assimétrico entre os grupos que participam de uma disputa para impor certos significados em detrimento de outros.

A centralidade da dimensão simbólica da cultura representa uma forma de análise em que a produção, distribuição e acesso aos bens culturais estão envolvidos com a maneira como valorizamos ou ignoramos certos aspectos da vida social. O ponto fundamental dessa discussão refere-se à compreensão de que os sentidos e significados historicamente construídos estão inseridos num processo conflituoso em que relações de poder caracterizam um combate por significado. Nesse combate, relações sociais são desfeitas e estabelecidas, conhecimentos são produzidos e distribuídos, políticas são geradas.

Tal abordagem traz para a produção de significados um campo de ação que engloba os investimentos concretos das pessoas no processo de dominação e resistência, não como pólos opostos, mas como inseridos no emaranhado das decisões e ações políticas cotidianas. Uma análise da cultura, neste contexto, não se realiza numa perspectiva em que temos de um lado os grupos dominantes que realizam aquilo que é considerado cultura e, de outro, grupos que reinventam essa cultura em proveito próprio. É preciso analisar as condições concretas, as relações hierarquizadas, os aspectos po- 
líticos e econômicos que fazem com que as relações de poder sejam, sobretudo, assimétricas.

É neste contexto que as práticas corporais são interpretadas: os esportes, as danças, as lutas, a ginástica, as brincadeiras infantis, etc., estão envolvidos nas formas como enxergamos questões sociopolíticas que envolvem a sociedade como um todo. Isto é, como as nossas visões sobre questões de raça, gênero, classe, idade, distribuição e produção do conhecimento, distribuição de solo urbano e rural, questões ligadas à saúde pública - como questões repletas de significados sociais - foram conformadas, aprendidas, vividas, problematizadas na nossa vivência com as diversas práticas corporais existentes.

Tais questões elegem reflexões importantes sobre a prática pedagógica da Educação Física. Ao trazer como referência a questão da produção de significados, a Educação Física passa a ser vista não como uma mera atividade em que são escolhidas técnicas supostamente livres de coerções, mas como uma produção e uma política cultural que busca compreender como os significados historicamente constituídos por diversos grupos para as práticas corporais encontram-se permeados por relações de poder para que determinados significados tornem-se hegemônicos em detrimento de outros.

A Educação Física é vista como uma prática pedagógica que se apropria das práticas corporais humanas e destina a elas um determinado trato pedagógico, participando da luta ou do processo de produção de significados. Os motivos pelos quais as pessoas se envolvem, por exemplo, em práticas esportivas, porque algumas modalidades são mais preferidas do que outras, porque algumas identidades de classe, raça ou gênero são identificadas com algumas práticas e não com outras, porque alguns esportes são motivos de intervenção política pública, dentre diversos outros aspectos, colocam a produção de significados no centro das preocupações daqueles que possuem a dimensão cultural como referência.

Ou seja, conceber a Educação Física e a escola como um importante elemento para a desestruturação das condições de produção de significados que conduzem as pessoas à condições desumanas de vida, considerando que para MCLAREN (2000, p. 123), a luta por condições dignas de existência pressupõe como tarefa central de nossas intervenções "(...) transformar as relações sociais, culturais e institucionais nas quais os significados são gerados".

Enfim, parece-me que as discussões aqui presentes apenas abrem caminhos para que diversas outras questões sejam trabalhadas. Os argumentos que utilizei são apenas estratégias em que a cultura é a ferramenta principal para levantar questões possíveis para refletir a prática pedagógica da Educação Física. Na realidade, uma análise paciente mostrará que muitas das coisas 
ditas são apenas interpretações ou comentários sobre o que autores da Educação Física vem discutindo há algum tempo. De qualquer forma, na turbulência é melhor se acalmar e encontrar conforto e forças para continuar nas palavras do poeta.

Nada está perdido para sempre/ Neste mundo há um tipo de progresso doloroso/ Lamentando o que ficou para trás e sonhando com o porvir/ Pelos, é o que eu acho.

Tony Kushner

\section{REFERÊNCIAS}

ALVES, V. de F. N. Uma leitura antropológica sobre a educação física e o lazer. In: WERNECK, C. L. G.; ISAYAMA, H. F. Lazer, recreação e educação física. Belo Horizonte: Autêntica, 2003. p. 83-114.

BRACHT, V. A criança que pratica esportes respeita as regras do jogo... capitalista. Revista Brasileira de Ciências do Esporte, São Paulo, v. 7, n. 2, p. 62-68, jan. 1986.

. Educação Física: conhecimento e especificidade. In: SOUZA, E. S. de; VAGO, T. M. Trilhas e partilhas: educação física na cultura escolar e nas práticas sociais. Belo Horizonte: Cultura, p. 13-24, 1997.

. A constituição das teorias pedagógicas da educação física. Cadernos Cedes, Corpo e Educação, Campinas, v. 19, n. 48, p. 69-98, ago. 1999.

. Saber e fazer pedagógicos acerca da legitimidade da Educação Física como componente curricular. In: CAPARROZ, F. E. (Org.). Educação Física escolar: política e intervenção, v. 1. Vitória: Proteoria, 2001. p. 67-79.

BRANDÃO, C. R. A educação como cultura. Campinas: Mercado das Letras, 2002.

DAOLIO, J. Educação Física e conceito de cultura. Campinas: Autores Associados, 2004.

. Cultura, educação fisica e futebol. Campinas: Unicamp, 1997.

GARCIA, S. G. Cultura, dominação e sujeitos sociais: tempo social. Revista de Sociologia, São Paulo, USP, v. 8, n. 2, p. 156-176, out. 1996.

GIROUX, H. A. Cruzando as fronteiras do discurso educacional: novas políticas em educação. Porto Alegre: Artes Médicas Sul, 1999. 
GRECO, P. J.; BENDA, R. N. (Orgs.). Iniciação esportiva universal: da aprendizagem motora ao treinamento técnico. Belo Horizonte: UFMG, 1998.

HALL, S. A centralidade da cultura: notas sobre as revoluções culturais do nosso tempo. Educação \& Realidade, Porto Alegre, v. 22, n. 2, p. 15-46, jul./dez. 1997.

KUNZ, E. Transformação didático-pedagógica do esporte. Ijuí: Unijuí, 2000.

MCLAREN, P. Multiculturalismo crítico. São Paulo: Cortez; Instituto Paulo Freire, 2000.

POPKEWITZ, T. S. História do currículo, regulação social e poder. In: SILVA, T. T. da (Org.). O sujeito da educação: estudos foucaultianos. Petrópolis: Vozes, 1994. p. 173-210.

SACRISTAN, J. G. A educação que temos, a educação que queremos. In: IMBERNÓN, F. A educação no século XXI: desafios do futuro imediato. Porto Alegre: Artes Médicas Sul, 2000, p. 37-76.

SILVA, T. T. da. O currículo como fetiche: a poética e a política do texto curricular. Belo Horizonte: Autêntica, 2001.

SOARES, C. L. et. al. Metodologia do ensino da educação física. São Paulo: Cortez, 1992.

TABORDA DE OLIVEIRA, M. A. de. Existe lugar para a EF na escola básica? In: CONGRESSO BRASILEIRO DE CIÊNCIAS DO ESPORTE, CONBRACE, 10., 1997, Goiânia. Anais... Goiânia (GO), 1997.

. Práticas pedagógicas da Educação Física nos tempos e espaços escolares: a corporalidade como termo ausente? In: BRACHT, V.; CRISORIO, R. A Educação Física no Brasil e na Argentina: identidade, desafios e perspectivas. Campinas: Autores Associados; Rio de Janeiro: Prosul, 2003. p. 147-154.

VAGO, T. M. Educação física escolar: temos o que ensinar? Revista Paulista de Educação Física, São Paulo, Suplemento 1, 1995.

. Intervenção e conhecimento na escola: por uma cultura escolar de Educação Física. In: GOELLNER, S. V. Educação física/ciências do esporte: intervenção e conhecimento. Florianópolis: CBCE, 1999. p. 17-36.

. A educação física na cultura escolar: discutindo caminhos para a intervenção e a pesquisa. In: BRACHT, V.; CRISORIO, R. A Educação Física no Brasil e na Argentina: identidade, desafios e perspectivas. Campinas: Autores Associados; Rio de Janeiro: Prosul, 2003. p. 197-222.

Texto recebido em 20 nov. 2004

Texto aprovado em 08 abr. 2005 